\title{
Effects of lesions in the basal ganglia on the retention of two-way active avoidance performance
}

\author{
CHARLES C. DUNCAN, W. GARY THOMPSON, and LESLIE H. HICKS \\ Howard University, Washington, D.C. 20059
}

\begin{abstract}
The effects of lesions in the globus pallidus, substantia nigra, and the parafascicular nuclei of the thalamus on the retention of an active avoidance task were studied. The role of these basal ganglia and thalamic nuclei in the speed of initiating an avoidance response was assessed. Lesions of the substantia nigra and the globus pallidus severely hindered retention performance of a two-way active avoidance response. Parafascicular lesions impaired performance to a lesser degree.
\end{abstract}

Hicks and Birren (1970), after reviewing the literature on age and brain correlates of psychomotor slowing, concluded that the basal ganglia were importantly involved in speed of initiating performance. For a number of years, Denny-Brown (1962, 1976) has proposed that a major role of the basal ganglia is in the initiation of movements. But there have been no direct experimental tests of these views.

Structures of the basal ganglia investigated in this study were the globus pallidus (GP) and the substantia nigra (SN). Because of its fiber connections with the globus pallidus (Scheibel \& Scheibel, 1967), the parafascicular nucleus (PF) of the thalamus was also studied.

Beatty and Siders (1977) reported that globus pallidus lesions impaired male rats in their acquisition of one-way and two-way active avoidance tasks. Female rats were impaired only on the two-way task. Levine, Ferguson, Kreinick, Gustafson, and Schwartzbaum (1971) found that lesions in the globus pallidus produced a deficit in leverpressing movement of the forelimb contralateral to the lesion.

Mitcham and Thomas (1972) found that substantia nigra lesions impaired acquisition performance of rats on a two-way avoidance task. Delacour (1971) reports that center median-parafascicular lesions produce a deficit on acquisition and retention of shuttle avoidance tasks in rats. But Bohus and De Wied (1967a, 1967b) found that parafascicular lesions did not hinder rats in the acquisition of an avoidance response, though large lesions to other midline thalamic structures, including center median, did. The present study investigated the effects of lesions in GP, SN, and PF on the retention of two-way avoid-

This research was supported by Research Grant 1 R01 NS 09630 to L.H.H. and completed during his stay at the Center for Advanced Study in the Behavioral Sciences, Stanford, California. Address reprint requests to Leslie $H$. Hicks, Psychology Department, Howard University, Washington, D.C. 20059. ance responding and on the latency of response to a brief warning signal.

\section{METHOD}

\section{Subjects}

Sixty-two Sprague-Dawley albino male rats were used in the experiment. The animals, weighing between 325 and $380 \mathrm{~g}$ at the beginning of testing, were housed in individual cages. Food and water were available on an ad-lib basis.

\section{Apparatus}

A Plexiglas, toggle-floor shuttlebox (Lehigh Valley Electronics) with dimensions of $51 \times 24 \times 27 \mathrm{~cm}$ was divided into two equal compartments by a metal barrier $7.62 \mathrm{~cm}$ high. The grid floor consisted of .64-cm-diam metal rods spaced $1.27 \mathrm{~cm}$ apart. The conditioned stimulus (CS) was a tone $(60 \mathrm{~Hz})$, whose audio source was mounted on top of the shuttlebox midway between the two compartments. The unconditioned stimulus (US) was .6-mA ac footshock delivered through the grid floor.

\section{Training Procedures}

On Day 1 of adaptation, each rat was allowed free exploration of both compartments of the shuttlebox for a 10-min period. Training procedures started the next day. The subject was placed in one compartment of the apparatus. The CS was presented for $5 \mathrm{sec}$. If the rat crossed to the other compartment during this 5-sec period, the CS was terminated simultaneously with the crossing. If the animal failed to cross after $5 \mathrm{sec}$, shock was administered and continued, along with the CS, until it crossed to the other side. Intertrial intervals of 25,30 , and $35 \mathrm{sec}$ were varied randomly. The interval between the onset of the CS and the onset of the US was progressively reduced during the course of the 10-day training period. For the first 5 days, the CS-US interval was $5 \mathrm{sec}$. For the next 3 days, the CS-US interval was $3.5 \mathrm{sec}$. Finally, on Days $9-10$, the CS-US interval was reduced to $2.5 \mathrm{sec}$. All animals received 25 trials per day.

Animals underwent surgery within $24 \mathrm{~h}$ after the completion of Day 10 of avoidance training. Postoperative, two-way active avoidance testing was given at 10 and 30 days after surgery. Each postoperative session consisted of 2 consecutive days of testing, 25 trials per day, at the 2.5 -sec CS-US interval. Mean number of avoidances and mean latencies were recorded for each session.

\section{Surgery \\ Surgery was done under Nembutal anesthesia $(50 \mathrm{mg} / \mathrm{kg})$.}

Globus pallidus lesions. Bilateral lesions were produced in 15 

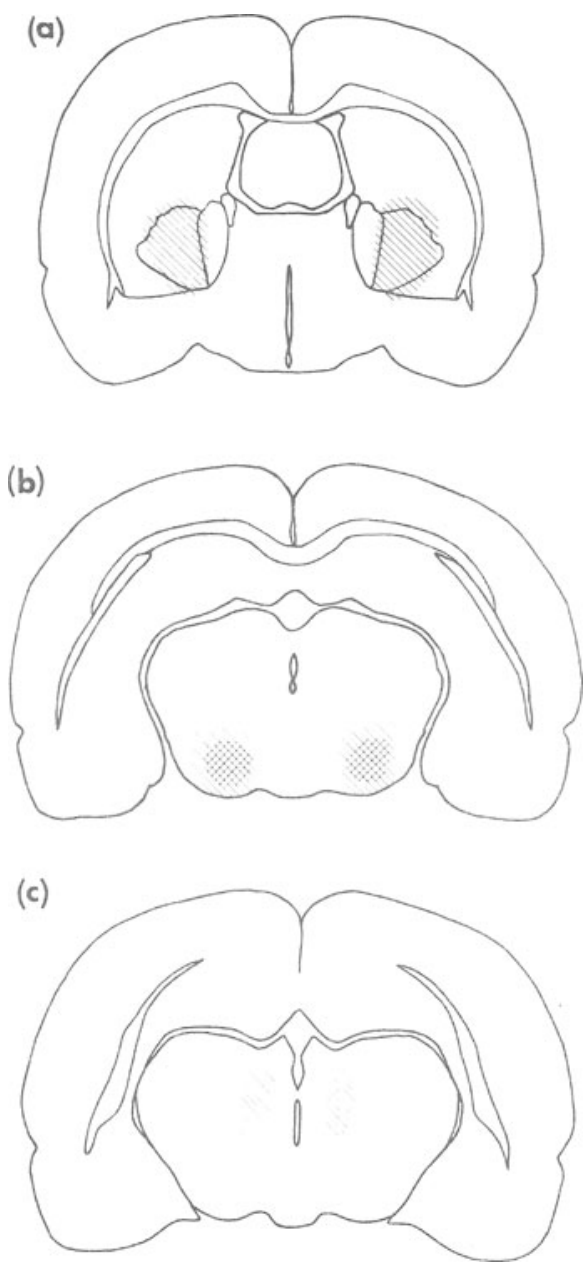

Figure 1. Representative lesions in globus pallidus (a), substantia nigra (b), and parafascicular (c) operated animals.

animals electrolytically by a $2.5-\mathrm{mA}$ current passed anodally for $10 \mathrm{sec}$ through a diamel-coated stainless steel electrode $(.5-\mathrm{mm}$ bared tip). The coordinates for these lesions were $.8 \mathrm{~mm}$ anterior to bregma, $3.2 \mathrm{~mm}$ lateral to midline, and $6.8 \mathrm{~mm}$ below the skull.

Substantia nigra lesions. Bilateral lesions were made in 14 animals by passing an anodal current of $1 \mathrm{~mA}$ through an electrode (.5-mm exposed tip) for $10 \mathrm{sec}$. The coordinates were $3.6 \mathrm{~mm}$ posterior to bregma, $2.4 \mathrm{~mm}$ lateral to midline, and $8.8 \mathrm{~mm}$ below the skull.

Parafascicular lesions. Twelve animals were bilaterally lesioned by an anodal current of $1.5 \mathrm{~mA}$ for $7 \mathrm{sec}$. The coordinates were $2.4 \mathrm{~mm}$ posterior to bregma, $1.3 \mathrm{~mm}$ lateral to midline, and $6.0 \mathrm{~mm}$ below the skull.

Control operations. Three animals had skull holes drilled at globus pallidus coordinates, three at substantia nigra coordinates, and two at parafascicularis coordinates. Electrodes were lowered but no current was passed.

Unoperates. Thirteen animals received no surgery.

\section{Histology}

When testing was completed, the operated animals were perfused intracardially with saline, followed by a $10 \%$ Formalin solution. The brains were removed and placed in Formalin for at least 7 days. Quick-frozen brain sections of $40 \mu$ were photo- graphed for verification of lesion placements. Results are reported only for those animals in which lesions were mainly confined to the aimed-for structures. Representative lesions are displayed in Figures $1 \mathrm{a}, 1 \mathrm{~b}$, and $1 \mathrm{c}$.

\section{RESULTS}

Weight losses, ranging from one-sixth to onefourth of preoperative levels, were seen in most of the animals in the SN and GP groups during the first week after surgery. But all had resumed eating and drinking by 10 days after the operation, and their weights had begun to recover. Thirty days after the operation, SN and GP weights had recovered beyond preoperative levels but not up to the levels of unoperated or control operated animals.

Figure 2 shows the mean number of avoidance responses for the various groups at Days 9-10 of preoperative testing and Days 10-11, 30-31 of postoperative testing. An analysis of variance of avoidance responses showed a significant difference from pre- to postoperative sessions $[F(2,114)=43.23, p<.0005]$ and among groups $[\mathrm{F}(4,57)=20.04, \mathrm{p}<.0005]$. The Sessions by Groups interaction was also significant $[F(8,114)=15.09, p<.0005]$. Newman-Keuls tests of individual comparisons showed that the SN and GP groups differed from the unoperated animals $(p<.01)$ and the control-operated animals $(p<.05)$. The PF group differed from the unoperated group $(p<.01)$, but there were no other significant paired comparisons. Individual comparisons of testing sessions by

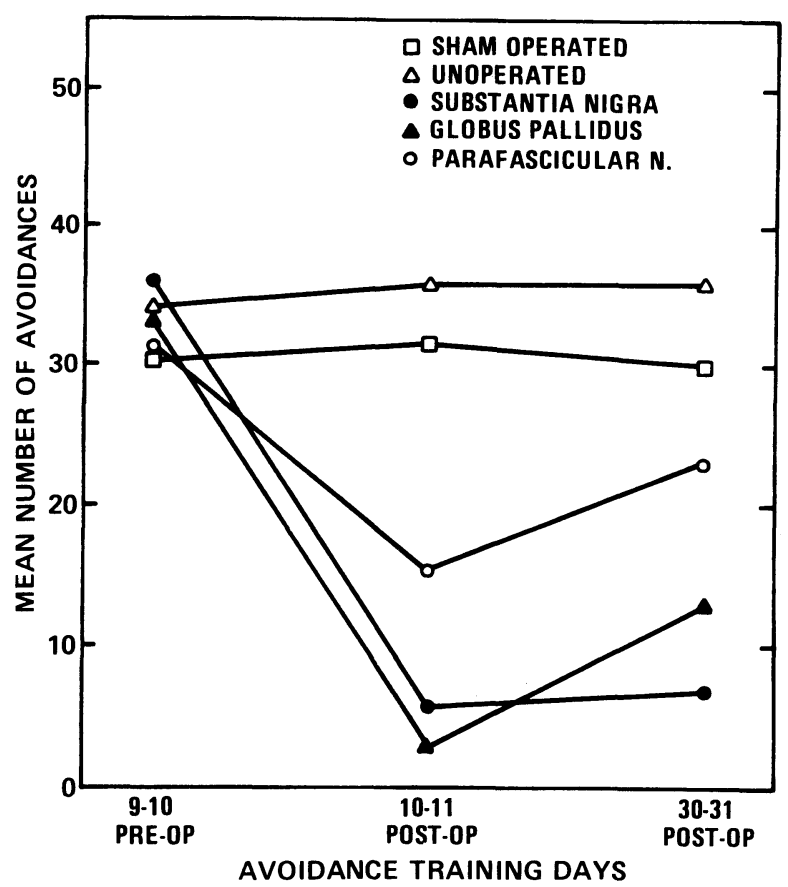

Figure 2. Mean number of avoidance responses at pre- and postoperative testing sessions. 
Table 1

Mean Latencies (in Seconds) of All Trials

\begin{tabular}{lrrrr} 
& & \multicolumn{3}{c}{ Days } \\
\cline { 3 - 5 } & & & \multicolumn{2}{c}{ Postoperative } \\
\cline { 3 - 5 } & $\mathrm{n}$ & $9-10^{*}$ & $10-11$ & $30-31$ \\
\hline Unoperated & 13 & 1.60 & 1.48 & 1.54 \\
Sham-Operated & 8 & 1.79 & 1.67 & 1.84 \\
Substantia Nigra & 14 & 1.43 & 2.33 & 2.32 \\
Globus Pallidus & 15 & 1.58 & 2.42 & 2.11 \\
Parafascicular n. & 12 & 1.67 & 1.93 & 1.96 \\
\hline
\end{tabular}

*Preoperative.

Newman-Keuls tests showed that both postoperative sessions differed from the preoperative session $(p<.01)$ and from each other $(p<.01)$. The least number of avoidance responses occurred 10-11 days after surgery.

Table 1 shows the mean latencies on the preoperative and postoperative testing sessions for the various groups. An analysis of variance showed significant differences among sessions $[\mathrm{F}(2,114)=30.16, \mathrm{p}<$ $.0005]$ and groups $[F(4,57)=9.73, p<.0005]$. The interaction between sessions and groups was significant $[F(8,114)=13.78, p<.0005]$. Newman-Keuls tests showed significant differences in latencies when both postoperative sessions were compared with the preoperative sessions $(p<.01)$. The postoperative sessions did not differ from each other on latencies. Individual comparisons of groups on latency scores showed that each of the operated groups differed from the unoperated group $(\mathrm{p}<.01)$ and that the $\mathrm{SN}$ and GP groups differed from the control operates $(p<.01)$. No other comparisons were significant.

\section{DISCUSSION}

Lesions of the globus pallidus and the substantia nigra severely impaired the retention of two-way active avoidance performance. Following these lesions, the number of avoidances declined and latency scores increased compared with preoperative levels and with the scores of unoperated animals. Parafascicular animals were only moderately impaired. All operated animals showed the greatest impairment 10 days after the operation. At 30 days after the operation, both pallidal and parafascicular animals improved their performance over the 10-day level. But the nigral animals did not improve from the first to the second postoperative testing. The retention deficit of the SN rats is consistent with the impaired acquisition performance on two-way active avoidance following SN lesions found by Mitcham and Thomas (1972). Impaired performance by our pallidal rats was similar to that reported on the acquisition of a two-way avoidance task by Beatty and Siders (1977) for male rats. In the Mitcham and Thomas study, SN-lesioned ani- mals averaged about $18 \%$ correct responses, while the male GP animals of Beatty and Siders averaged about $30 \%$ correct responses. The SN and GP animals in the present study averaged less than $10 \%$ correct responses. The shorter warning signal duration (2.5 sec in our study, compared with Mitcham and Thomas' $5 \mathrm{sec}$ and Beatty and Siders' $10 \mathrm{sec}$ ) might have made our task more difficult.

The parafascicular rats in the present study performed similarly to Delacour's (1971) rats with lesions in the center median-parafascicular complex; that is, there was about a $45 \%$ postoperative decline in correct responses. Delacour also reports an even greater deficit on two-way avoidance acquisition by his operated animals in contrast with the results of Bohus and DeWied (1967a, 1967b), whose parafascicular animals were unaffected in the acquisition of this task.

Our lesion effect measures were all on retention performance, and one might expect that this performance would be better than acquisition performance of lesioned animals on the same task. Compared with the data of an earlier study (Delacour, 1971), this occurred for our parafascicular rats. But our SN and GP animals performed even worse on retention than did the SN animals of Mitcham and Thomas (1972) and worse on the acquisition of a two-way active avoidance task than did the GP animals of Beatty and Siders (1977).

The number of avoidance responses was so few in rats with lesions of the basal ganglia that no statistical comparisons were made of the latencies on just those trials in which the subjects avoided the shock. But an inspection of these latencies and observations of the animal's movements showed that operated rats were still capable of rapid movements once they began the response. The failure to avoid was a failure to initiate movement in response to a warning signal.

This deficit in responding rapidly after lesions in these basal ganglia nuclei supports the hypothesis of Hicks and Birren (1970) that these structures are importantly involved in the speed of initiating and executing movements. That the deficit is greater following lesions of the globus pallidus and substantia nigra is not surprising, given the greater size and complexity of neural circuitry of these nuclei in comparison with the intralaminar nuclei of the thalamus which received lesions in this study.

\section{REFERENCES}

Beatty, W. W., \& Siders, W. A. Effects of small lesions in the globus pallidus on open-field and avoidance behavior in male and female rats. Bulletin of the Psychonomic Society, 1977, 10, 98-100.

BohUs, B., \& DE WIED, D. Avoidance and escape behavior following medial thalamic lesions in rats. Journal of Comparative and Physiological Psychology, 1967, 64, 26-29. (a)

Boнus, B., \& DE WIED, D. Failure of $\alpha$-MSH to delay extinction 
of conditioned avoidance behavior in rats with lesions in the parafascicular nuclei of the thalamus. Physiology \& Behavior, 1967, 2, 221-223. (b)

Delacour, J. Effects of medial thalamic lesions in the rat. A review and an interpretation. Neuropsychologia, 1971, 9, 157174.

Denny-Brown, D. The basal ganglia and their relation to disorders of movement. London: Oxford University Press, 1962.

Denny-Brown, D., \& Yanagisawa, N. The role of the basal ganglia in the initiation of movement. In M. D. Yahr (Ed.), The basal ganglia. New York: Raven Press, 1976.

Hicks, L. H., \& Birren, J. E. Aging, brain damage, and psychomotor slowing. Psychological Bulletin, 1970, 74, 377-396.

Levine, M. S., Ferguson, N., Kreinick, C. J., Gustafson,
C. W., \& Schwartzbaum, J. S. Sensorimotor dysfunctions and aphagia and adipsia following pallidal lesions in rats. Journal of Comparative and Physiological Psychology, 1971, 77, 282-293.

Mitcham, J. C., \& Thomas, R. K. Effects of substantia nigra and caudate nucleus lesions on avoidance learning in rats. Journal of Comparative and Physiological Psychology, 1972, 81, 101-107.

Scheibel, M. E., \& Scheibel, A. B. Structural organization of nonspecific thalamic nuclei and their projection toward cortex. Brain Research, 1967, 6, 60-94.

(Received for publication July 6, 1979; revision accepted January 21, 1981.) 